\title{
THE EFFECTS OF EMOTIONAL WORKING MEMORY TRAINING ON TRAIT ANXIETY
}

\author{
Gabrielle Veloso, \& Welison Evenston Ty \\ Ateneo de Manila University (Philippines)
}

\begin{abstract}
Trait anxiety is a pervasive tendency to attend to and experience fears and worries to a disproportionate degree, across various situations. This study sought to determine if participants who undergo emotional working memory training will have significantly lower scores on the trait anxiety scales post-intervention. The study also sought to determine if emotional regulation mediated the relationship between working memory training and trait anxiety. Trait anxiety was measured using the form Y2 of the Spielberger State-Trait Anxiety Inventory (STAI-Y2). Emotion regulation was measured using the Emotional Regulation Questionnaire (ERQ). Forty-nine participants underwent 20 days of computerized emotional working memory training called Emotional Dual n-back, which involves viewing a continuous stream of emotional content on a $3 \times 3$ grid, and then remembering the location and color of items presented on the grid. The control group consisted of fifty-one participants. Participants of the treatment group had significantly lower trait anxiety compared to controls post-intervention. Mediation analysis determined that working memory training was significantly related to trait anxiety reduction as measured by the STAI-Y2. Emotion regulation was found not to mediate between working memory training and trait anxiety reduction. Results suggest that working memory training may be useful in reducing psychoemotional symptoms of trait anxiety. Moreover, it proposes for future research to further look into the mediating role of emotion regulation via neuroimaging and the development of more comprehensive measures of emotion regulation.
\end{abstract}

Keywords: Trait anxiety, working memory, intervention, training, emotion regulation.

\section{Introduction}

Trait anxiety is a pervasive tendency to attend to and experience fears and worries to a disproportionate degree, across various situations. Decreased vulnerability to trait anxiety has been linked to having higher working memory capacity and better emotion regulation; however, the relationship between these factors has not been well-established.

\section{Objective}

This study sought to determine if participants who undergo emotional working memory training will have significantly lower trait anxiety post-training. The study also sought to determine if emotion regulation mediated the relationship between working memory training and trait anxiety.

\section{Method}

An experimental group comprising of 49 participants underwent 20 days of computerized emotional working memory training, which involved viewing a continuous stream of emotionally-charged content on a $3 \times 3$ grid, and then remembering the location and color of items presented on the grid. The control group comprised of 51 participants.

\section{Results}

Participants of the experimental group had significantly lower trait anxiety compared to controls, post-training. Subsequent mediation analysis determined that working memory training capacity gains were significantly related to anxiety reduction as measured by form Y2 of the Spielberger State-Trait Anxiety Inventory (STAI-Y2). Emotion regulation, as measured by the Emotional Regulation 
Questionnaire (ERQ), was found not to mediate between working memory capacity gains and trait anxiety reduction.

\section{Conclusion}

Working memory capacity gains and reductions in levels of trait anxiety were observed following emotional working memory training. The study may therefore be useful in informing interventions targeted at improving working memory capacity, and reducing levels of trait anxiety. Moreover, it proposes for future research to further look into the mediating role of emotion regulation via the development or utilization of more comprehensive measures of emotion regulation

Table 1. Measure of Effect of Mediator Variable

\begin{tabular}{lccc}
\hline Model & R Squared & $\begin{array}{c}\text { R Squared } \\
\text { Change }\end{array}$ & $\%$ \\
\hline Model with Working Memory Capacity Gains & 0.0923 & - & - \\
& & & \\
Model with Working Memory Capacity Gains + & 0.2524 & 0.1601 & 16.01 \\
\hline \begin{tabular}{l} 
Emotion Regulation Gains \\
\hline
\end{tabular}
\end{tabular}

\section{References}

Aikins D E, Craske M G. (2001). Cognitive theories of generalized anxiety disorder. Psychiatric Clinics of North America, 24(1), 57-74.

Beloe P, Derakshan N. (2019). Adaptive working memory training can reduce anxiety and depression vulnerability in adolescents. Developmental Science, doi:10.1111/desc.12831.

Berti, S. (2016). Switching Attention Within Working Memory is Reflected in the P3a Component of the Human Event-Related Brain Potential. Frontiers in Human Neuroscience, 9. doi:10.3389/fnhum.2015.00701

Cisler JM, Olatunji BO, Feldner MT, Forsyth J P. (2010). Emotion Regulation and the Anxiety Disorders: An Integrative Review. J Psychopathol Behav Assess, 32(1),68-82.

Culpepper, L. \& Conner, K. (2004). Effective recognition and treatment of generalized anxiety disorder in primary care. The Primary Care Companion to The Journal of Clinical Psychiatry, 6(1), 35-41.

Dennis, T. A., \& Hajcak, G. (2009). The late positive potential: a neurophysiological marker for emotion regulation in children. Journal of child psychology and psychiatry, and allied disciplines, 50(11), 1373-1383.

Ecker UK, Lewandowsky S, Oberauer K, Chee A E. (2010). The components of working memory updating: an experimental decomposition and individual differences. J Exp Psychol Learn Mem Cogn, 36(1), 170-189.

Enebrink P, Björnsdotter A, Ghaderi A. (2013). The Emotion Regulation Questionnaire: Psychometric properties and norms for Swedish parents of children aged 10-13 years. Euro J Psychology, 9(2), 289-303.

Engle, R. W. (2002). Working memory capacity as executive attention. Curr. Dir. Psychol. Sci, 11, 19-23. doi: 10.1111/1467-8721.00160

Eysenck MW, Derakshan N, Santos R, \& Calvo M G. (2007). Anxiety and cognitive performance: attentional control theory. Emotion, 7(2),336-53.

Foti D \& Hajcak G. (2008). Deconstructing reappraisal: descriptions preceding arousing pictures modulate the subsequent neural response. Journal of Cognitive Neuroscience, 20(6),977-88.

Franken I. (2014). Tackling Depression and Anxiety: A Working Memory Intervention. ClinicalTrails.gov [Available from: https:/clinicaltrials.gov/ct2/show/NCT02119923]

Gellman MD. (2012). Encyclopedia of behavioral medicine. New York, NY: Springer.

Gross JJ, John O P. (2003). Individual differences in two emotion regulation processes: implications for affect, relationships, and well-being. J Pers Soc Psychol, 85(2),348-62.

Gyurak, A., Goodkind, M. S., Kramer, J. H., Miller, B. L., \& Levenson, R. (2012). Executive functions and the down-regulation and up-regulation of emotion. Cognition \& Emotion, 26, 103-118.

Hadwin JA, Richards H J. (2016). Working Memory Training and CBT Reduces Anxiety Symptoms and Attentional Biases to Threat: A Preliminary Study. Front Psychol,7,47.

Kashdan TB, Zvolensky MJ, McLeish A C. (2008). Anxiety sensitivity and affect regulatory strategies: individual and interactive risk factors for anxiety-related symptoms. J Anxiety Disord, 22(3), 429-40. 
Kensinger EA, Corkin S. (2003). Effect of negative emotional content on working memory and long-term memory. Emotion, 3(4),378-393.

Lee TW, Xue S W. (2018). Does emotion regulation engage the same neural circuit as working memory? A meta-analytical comparison between cognitive reappraisal of negative emotion and 2-back working memory task. PLoS One, 13(9).

Leone de Voogd E, Wiers RW, Zwitser RJ, Salemink E. (2016). Emotional working memory training as an online intervention for adolescent anxiety and depression: A randomised controlled trial. Aust $J$ Psychol, 68(3),228-38.

Mammarella N. (2014). Is Emotional Working Memory Training a New Avenue of AD Treatment? A review. Aging Dis, 5(1), 35-40.

Miyake, A., Friedman, N. P., Emerson, M. J., Witzki, A. H., Howerter, A., \& Wager, T. D. (2000). The unity and diversity of executive functions and their contributions to complex "frontal lobe" tasks: a latent variable analyses. Cogn. Psychol, 41, 49-100. doi: 10.1006/cogp.1999.0734

Onraedt T, Koster E H. (2014). Training working memory to reduce rumination. PLoS One, 9(3).

Opitz C, Gross J, \& Urry L. (2012). Selection, optimization, and compensation in the domain of emotion regulation: applications to adolescence, older age, and major depressive disorder. Social and Personality Psychology Compass, 6(2),142-155.

Pe ML, Raes F, Kuppens P. (2013). The cognitive building blocks of emotion regulation: ability to update working memory moderates the efficacy of rumination and reappraisal on emotion. PLoS One, $8(7)$.

Redick TS, Broadway JM, Meier ME, Kuriakose PS, Unsworth N, Kane MJ, et al. (2012). Measuring working memory capacity with Automated Complex Span Tasks. Euro J Psychological Assessment, 28(3), 164-171.

Roughan L, Hadwin J A. (2011). The impact of working memory training in young people with social, emotional and behavioural difficulties. Learning and Individual Differences, 21(6),759-64.

Sari BA, Koster EH, Pourtois G, Derakshan N. (2015) Training working memory to improve attentional control in anxiety: A proof-of-principle study using behavioral and electrophysiological measures. Biol Psychol, 121, 203-12.

Schmeichel BJ, Volokhov RN, \& Demaree H A. (2008). Working memory capacity and the self-regulation of emotional expression and experience. J Pers Soc Psychol, 95(6), 1526-40.

Schweizer S, Grahn J, Hampshire A, Mobbs D, Dalgleish T. (2013). Training the emotional brain: improving affective control through emotional working memory training. J Neurosci, 33(12), 5301-11.

Schweizer S, Hampshire A, Dalgleish T. (2011). Extending brain-training to the affective domain: increasing cognitive and affective executive control through emotional working memory training. PLoS One, 6(9).

Spielberger CD, Gorsuch RL, Lushene R, Vagg PR, Jacobs G A. (1983). Manual for the State-Trait Anxiety Inventory. Palo Alto: Consulting Psychologists Press.

Takeuchi H, Taki Y, Nouchi R, Hashizume H, Sekiguchi A, Kotozaki Y, et al. (2014). Working memory training improves emotional states of healthy individuals. Front Syst Neurosci, 8,200.

Turner ML, Engle RW.(1989). Is working memory capacity task dependent? J Memory and Language, 28(2), 127-154.

Unsworth N, Heitz RP, Schrock JC, Engle R W. (2005). An automated version of the operation span task. Behav Res Methods, 37(3), 498-505.

Veerapa, E., Grandgenevre, P., El Fayoumi, M. (2020). Attentional bias towards negative stimuli in healthy individuals and the effects of trait anxiety. Sci Rep, 10,11826.

Vitasari P, Wahab MN, Herawan T, Othman A, Sinnadurai S K. (2011). Re-test of State Trait Anxiety Inventory (STAI) among Engineering Students in Malaysia: Reliability and Validity tests. Procedia-Social and Behavioral Sciences, 15,3843-3848.

Wanmaker S, Geraerts E, Franken I H. (2015). A working memory training to decrease rumination in depressed and anxious individuals: a double-blind randomized controlled trial. J Affect Disord, 175,310-9.

Wanmaker S, Hopstaken JF, Asselbergs J, Geraerts E, Franken I H. (2014). Decreasing dysphoric thoughts by a working memory training: A randomized double-blind placebo-controlled trial. $J$ Depress Anxiety, 3(165), 2167-1044.

Wilhelm, O., Hildebrandt, A., \& Oberauer, K. (2013). What is working memory capacity, and how can we measure it?. Frontiers in Psychology, 4. doi:10.3389/fpsyg.2013.00433

Williams JMG, Watts FN, MacLeod C, Mathews A. (1988). Cognitive psychology and emotional disorders. Wiley: Chichester.

Xiu L, Wu J, Chang L, Zhou R. (2018). Working Memory Training Improves Emotion Regulation Ability. Sci Rep, 8(1),15012. 